\title{
MUCK PROBLEMS IN SUBWAY SHIELD TUNNELING IN SANDY COBBLE STRATUM
}

\author{
Kai CUI \\ Weikang LIN \\ Key Laboratory of Transportation Tunnel Engineering of the Ministry of Education , Southwest \\ Jiaotong University, Chengdu, 610031, China \\ School of Civil Engineering, Southwest Jiaotong University, Chengdu, 610031, China
}

\begin{abstract}
Experiments aiming at the muck improvement for Chengdu's subway shield tunneling in water-rich sandy cobble ground initially finds out the kinds and ratio of muck improver suitable for the this strata, and through the field application determines the reasonable ratio of muck improver for shield tunneling in sandy cobble ground, providing a reference to other muck improvement for shied tunneling in similar ground. And the earth pressure balanced shield is widely used in tunnel engineering, with its characteristics as wide adaptability, safe operation, fast driving speed, low environmental noise and low cost. Taking Chengdu Metro Line as the background, aiming at the difficulty faced by EPB shield tunneling in water-rich sandy cobble ground, and based on the explorations and researches of the predecessors and scholars, engineering and technical personnel, the present paper combines with engineering examples to make a systematic summary and research on key construction technology of EPB shield tunneling through sandy cobble ground from the aspects of EPB shield adaptability, , structure and transformation of cutter and helical unearthed wares, settlement control method, and muck improvement measures. It has certain reference value and guiding significance to the selection of shield machine and the reconstruction of shield machine in complex geological condition.
\end{abstract}

Keywords: shield, sandy cobble ground, muck improvement

\section{INTRODUCTION}

The key of earth pressure balanced shield is to adjust the soil mass in the pressure chamber to a "plastic flow state" [1]. In order to get ideal muck which is beneficial for EPB shield tunneling, scholars all over the world have made a large number of experimental studies [2]. These studies mainly use foaming agent, bentonite, polymers and their combination for musk improvement [3], and rarely involve musk improvement for EPB shield tunneling in water-rich sandy cobble stratum; In addition, there are no examples to take reference in the past of EPB shield tunneling. Therefore Chengdu muck improvement for EPB shield tunneling in water-rich sandy cobble stratum water is crucial EPB shield tunneling. The muck improvement effect will directly affect the speed of shield machine driving, driving cost, and even the success of the construction project.

\section{GENERAL SITUATION OF THE PROJECT}

Chengdu sandy cobble stratum is rich in groundwater with large particles porosity and strong water permeability, the pebbles are working as skeleton in the soil, making the structure loose; The pebble content is high, and pebbles are mainly sub - circular with a small amount of circular ones. It has poor sorting, and filled mainly with fine sand and medium sand; - Boulders are randomly distributed in stratum; according to the scene digging situation, maximum size of boulder is above $200 \mathrm{~mm}$; less amount of mud is contained in sandy cobble stratum, belonging to the category of non-cohesive granular 
soil. Figurel is sandy cobble soil dug out in shield tunneling of Chengdu Metro Line.

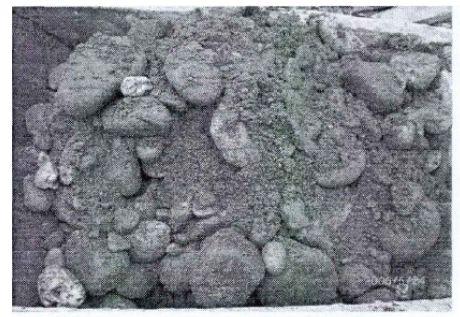

(a) Sandy cobble soil after digging and mixing

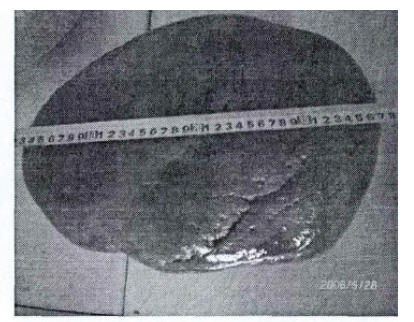

(b) Single sandy cobble

Fig.1 The Dug out Sandy cobble Soil

\section{ANAYSIS OF CHENGDU WATER-RICHED SANDY COBBLE STRATUM}

Test materials are selected from sandy cobble stratum buried in different depths of Chengdu metro line and 3 sample groups are selected. The first group is slightly dense sandy cobble layer; the second is middle dense sandy cobble layer; the third group is a highly dense sandy cobble layer. The grades of typical particle obtained from construction field are shown in Tablel. The uneven coefficient and the curvature coefficient indicate that the stratum is a poorly graded. The mud content is relative low, belonging to the non-cohesive granular soil. Based on the relative density test, the density of sandy cobble in natural state is relatively large, which means that sandy cobble in natural state is relatively dense. And the measured gradation of sandy cobble is shown in Table1.

There are plain filled soil and sandy cobble along with Chengdu Metro line. The mechanical properties of sandy cobble stratum are distributed very uneven. And based on this experiment, and survey report of Chengdu Metro Line, the physic-mechanical parameters of plain filled soil, slightly dense sandy cobble soil, middle dense sandy cobble soil and highly dense sandy cobble soil is shown in Table2.

Tab.2 Physic-mechanical Parameters of soils

\begin{tabular}{|c|c|c|c|c|c|}
\hline Soil Name & 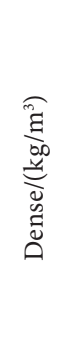 & 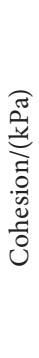 & 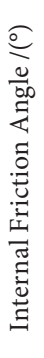 & 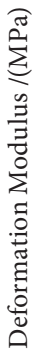 & 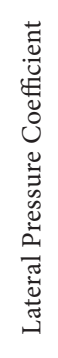 \\
\hline plain filled soil & 1800 & 15 & 20 & 6 & 0.43 \\
\hline $\begin{array}{l}\text { slightly dense } \\
\text { sandy cobble soil }\end{array}$ & 2000 & 0 & 38 & 20 & 0.30 \\
\hline $\begin{array}{l}\text { middle dense } \\
\text { sandy cobble soil }\end{array}$ & 2100 & 0 & 44 & 28 & 0.25 \\
\hline $\begin{array}{l}\text { highly dense sandy } \\
\text { cobble soil }\end{array}$ & 2200 & 0 & 48 & 38 & 0.20 \\
\hline
\end{tabular}

\section{SHIELD DIGGING PROBLEMS}

Because of poor cementation and different particle size of sandy cobble soil, sandy cobble soil with high big-size cobble will have great volume of stone of (see Figure 2). The cobble in sandy cobble stratum has big particle size, high strength and low cohesion. The force of the soil mass is transferred among individual particles and the stratum is characterized by a non continuous structure, so sandy cobble stratum has a very strong dispersion quality. And the combination with relatively abundant groundwater will result poor plastic flow of musk in soil tank which can not meet the need of EPB shield. In the actual construction process, the poor muck plastic flow often leads to the various situations such as failure of establishing EPB cutting face, surface over-break and settlement controlling difficult, spiral machine spewing, mechanical failure, tool consumption seriously, the shield machine cutter disc stuck caused by tool large thrust and torque.

Tab.1 Gradation of Sandy cobble in Chengdu Subway

\begin{tabular}{|c|c|c|c|c|c|c|c|c|c|}
\hline particle size & $>200$ & $200-100$ & $100-60$ & $60-40$ & $40-20$ & $20-10$ & $10-5$ & $5-2$ & $<2$ \\
\hline$/ \mathrm{mm}$ & \multicolumn{9}{|c|}{ mass percent $/ \%$} \\
\hline slightly dense sandy cobble & 0 & 9.6 & 17.3 & 15.7 & 16.8 & 3.3 & 0.7 & 0.9 & 35.7 \\
\hline middle dense sandy cobble & 0.4 & 10.5 & 20.4 & 19.2 & 17.6 & 2.9 & 0.6 & 0.8 & 27.6 \\
\hline highly dense sandy cobble & 0.5 & 11.6 & 23.6 & 24.2 & 20.2 & 2.7 & 0.5 & 0.5 & 16.2 \\
\hline
\end{tabular}




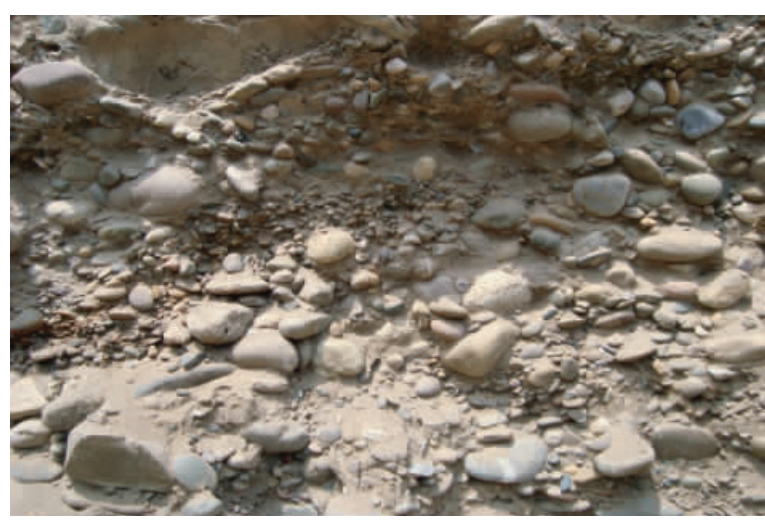

Fig.2 Sandy Cobble Stratum with High Content of Big-sized Cobble

\section{COUNTERMEASURES AND SOLUTIONS}

First of all, the musk in soil warehouse and screw conveyor should have good plastic fluidity. This is mainly to enable Jack's force on clapboard being averagely and regularly put in digging surface, and ensure the dug out muck can be continuously sent to screw conveyor. Therefore, it can avoid the muck stacked at low-voltage part of soil warehouse, the adhesion to cutter disc and the blockage to soil warehouse, avoiding the rise of rotation torque and driving torque of the cutter disc and screw conveyor. Musk cut down by the disk is conveyed by screw conveyor from the pressure chamber to tunnel under barometric pressure. If brake gear is used in the transportation from screw conveyor to belt conveyor, muck should also have low permeability. Low permeability can avoid water in muck going through $\mathrm{t}$ screw conveyor. In addition, front center of cutter disc should be arranged with foam injection hole which can reduce the permeability of the excavation, avoiding the water infiltration on the excavation face, and maintaining stability of the excavation face. In addition, there is a very important requirement for the construction muck, namely: the internal friction angle of the muck should be relatively small. If the internal friction angle of the muck is large, frictional resistance of the soil will increase. This will lead to the poor fluidity of the muck; on the other hand it will increase the thrust of cutter disc torque, screw conveyor and shield Jack, failing the excavation of soil. In order to successfully carry out EPB shield tunneling, the mechanical properties of soil should be met: 1) soil mass should not be easy to drainage and consolidation (not easy to "incrust"); 2) soil mass should be in plastic flow state (easy to transfer under pressure and stir); 3) soil mass should have water-tightness (does not occur "spewing situation").

\section{MUCK IMPROVEMENT METHODS}

The usual way is to inject some materials into pressure ware to improve soil state and makes it meet the construction requirements. Generally used materials can be divided into four categories. These materials are sometimes used alone, and sometimes used in combination. Their characteristics are summarized as follows:

\section{1) Minerals}

In order to make the excavated soil become mud with fluidity and permeability, some fine particles need to add in. According to shield tunneling experience, the content of fine particles in excavated soil must reach about 30\%-35\%. If the fine particles in excavated soil are insufficient, the most commonly way is to produce mud with bentonite, montmorillonite and other materials to make up the insufficiency.

2) High water- absorbent resin

Because high water-absorbent resin can absorb groundwater with weight of several hundred times of itself into gel state, it has good effect on preventing the spewing of the foundation with high water pressure. But in high concentrations of salt water or the foundation containing a large number of irons, copper and other metals, and foundations with strong acid, strong alkaline and chemical reinforcement range, its water absorption capacity will be greatly reduced.

3) Water soluble polymer

It is a polymer material same as resin, which has the effect of increasing the viscosity of the soil with good pumping performance. In past shield tunneling, CMC is used in many cases. But sometimes muck will become mushy state and it will be treated as industrial waste.

4) Interfacial active material

It is current advanced method to improve the properties of the soil, which is injecting foams that are made by special foaming agent and compressed air. At present, domestic shield tunneling mainly uses bentonite and foam as muck improvement admixture. But, water-absorbent resin and water soluble polymer materials are used relatively rare. TAC polymer is creatively introduced into Kuizu shield tunneling in waterrich sandy stratum. TAC polymer has excellent hydrophilicity and significant effect of increasing viscosity. It can improve fluidity and water-tightness of water-rich sandy stratum and prevent the incrusting of cutter disc. This admixture is well applied in Kuiqu shield tunneling in water-rich sandy cobble stratum. The appearance and experimental results of TAC polymer are shown in Figure 3.
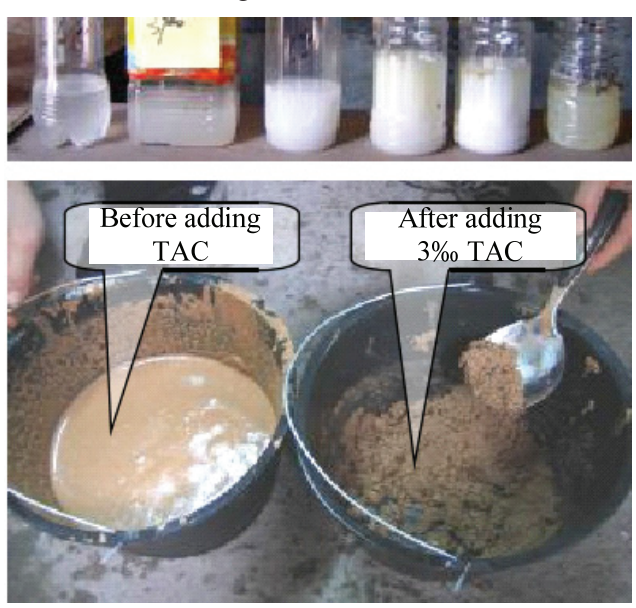

Fig. 3 The appearance and experimental results of TAC polymer 
According to the analysis of particle composition and physical-mechanical parameters of sandy cobble stratum, muck improvement for shield tunneling in this stratum needs to solve the following problems:

1. Improve the anti-permeability of muck in soil ware to avoid large surface subsidence or collapse caused by drainage consolidation on face;

2. Increase the fluidity of muck in soil ware to avoid occlusion accident by poor dumping poor;

3. Reduce internal friction angle of muck in soil ware and soil in tunnel face to reduce the friction to cutter disc and a cutter wear as well as cutter disc torque;

4. Improve the plasticity of muck in soil ware to avoid incrusted accidents caused by adhesion of muck on cutter disc.

Through the above analysis, interfacial active material compared with other modified agents is more suitable for muck improvement in Chengdu shield tunneling in waterrich sandy cobble stratum. So in the construction of Chengdu subway, foaming agent is used to improve muck.

\section{APPLICATION OF FOAMING SYSTEM IN MUCK IMPROVEMENT}

Foaming system [4] in shield tunneling of this project consists of six roads (single pump and single supply). It is mainly composed of foam liquid pump, high pressure (40bar lbar $=0.1 \mathrm{MPa}$ ) three cylinder plunger pump, electromagnetic flow meter (gas, liquid), electric ball valve, foam generator, pressure sensors, pipeline components and other components. Figure 4 shows working principle of foam and bentonite system, as well as the position of cutter disc nozzle.

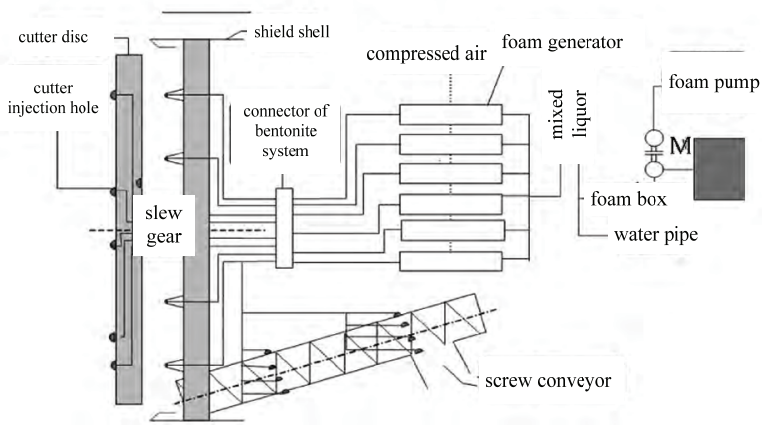

Fig.4 Working Principle of Foaming System

Under the condition of maintaining certain pressure in soil ware during tunneling, shield tunneling parameters are significantly improved through injecting foam into tunnel face. Add foam with the ratio of $30 \%$ to make tunneling average speed of 33-37 ring reach $44 \mathrm{~mm} / \mathrm{min}$, the total thrust of the jack be reduced by about $22.4 \%$, and the torque of the cutter be reduced by about $18.30 \%$; After adding foams in tunneling process, muck discharged from the soil ware is at plastic flow state, and shield tunneling is normal. And surface settlement has been effectively controlled. Specific tunneling parameters are shown in Table3 and Table4 [5-7].

Tab.3 Tunneling Parameters of Sandy Cobble Stratum without Foams

\begin{tabular}{|c|c|c|c|c|c|c|}
\hline 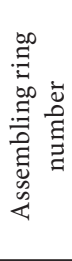 & 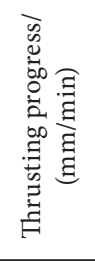 & 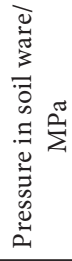 & 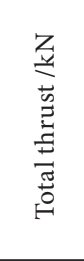 & 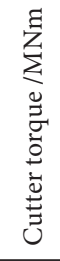 & 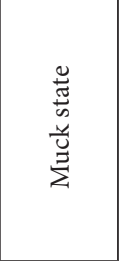 & 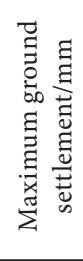 \\
\hline 15 & $6-20$ & 0.221 & 14.192 & 4.32 & spewing & $+4 /-27$ \\
\hline 16 & $12-25$ & 0.217 & 15.256 & 4.43 & $\begin{array}{c}\text { water } \\
\text { and soil } \\
\text { separation }\end{array}$ & $+6 /-24$ \\
\hline 17 & $9-19$ & 0.218 & 14.681 & 4.35 & $\begin{array}{c}\text { difficulty } \\
\text { in sending } \\
\text { soil }\end{array}$ & $+6 /-28$ \\
\hline 18 & $7-15$ & 0.224 & 14.697 & 4.26 & Spewing & $+5 /-25$ \\
\hline 19 & $0-10$ & 0.210 & 16.273 & 4.59 & $\begin{array}{c}\text { difficulty } \\
\text { in sending } \\
\text { soil }\end{array}$ & $+3 /-29$ \\
\hline
\end{tabular}

Tab.4 Tunneling Parameters of Sandy Cobble Stratum with Foams

\begin{tabular}{|c|c|c|c|c|c|c|}
\hline 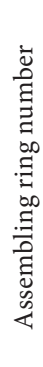 & 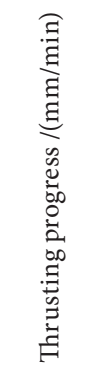 & 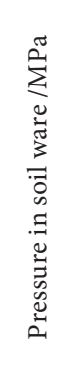 & 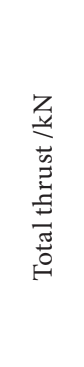 & 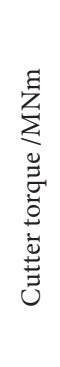 & 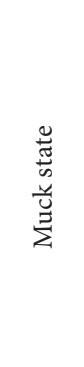 & 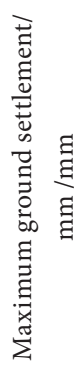 \\
\hline 33 & $35-52$ & 0.213 & 11.356 & 3.67 & $\begin{array}{c}\text { plastic } \\
\text { flow }\end{array}$ & $+3 /-17$ \\
\hline 34 & $26-43$ & 0.221 & 11.487 & 3.71 & $\begin{array}{l}\text { plastic } \\
\text { flow }\end{array}$ & $+3 /-20$ \\
\hline 35 & $41-65$ & 0.215 & 11.689 & 3.56 & $\begin{array}{l}\text { plastic } \\
\text { flow }\end{array}$ & $+4 /-16$ \\
\hline 36 & $37-56$ & 0.219 & 11.947 & 3.52 & $\begin{array}{l}\text { plastic } \\
\text { flow }\end{array}$ & $+3 /-18$ \\
\hline 37 & $38-54$ & 0.216 & 11.773 & 3.48 & $\begin{array}{l}\text { plastic } \\
\text { flow }\end{array}$ & $+2 /-14$ \\
\hline
\end{tabular}

According to the geological and environmental conditions of Chengdu subway, the main role of the foam in EPB shield tunneling is to reduce the mechanical wear of shield machine. When tunneling in soil mass with large friction, cutting tools of EPB shield machine are easy to be worn out. Bt injecting 
foam on the cutter disc, friction of soil mass and wear of cutter can be reduced. Adjust plastic fluidity in soil ware smooth. In EPB shield tunneling, soil nature will directly influence the shield tunneling process. Muck after cutting has good plasticity and fluidity, which can not only can make tunneling surface maintain good support pressure, and ensure the smooth implementation of soil conveying. In shield tunneling, due to the change of the stratum, soil in ware is difficult to possess the expected plastic fluidity which will lead to "incrusting" and "jamming" problems, seriously affecting tunneling efficiency. This problem can be solved effectively by injecting foam. Reduce water permeability of muck, because when EPB shield machine works in the gravel layer with strong water permeability, high water pressure on tunneled face will lead to a large number of groundwater loss at or even spewing at the export of screw conveyor which seriously effects the shield tunneling. Injection of foam can effectively reduce the permeability of muck, and effectively prevent tunneling spewing. Reduce internal friction of cutting muck which will reduce wear of cutter disc, screw conveyor, as well as cutting wheel torque. It will prevent mechanical malfunction caused by heating of high energy consumption.

\section{CONCLUSION}

Due to the fact that there are few researches both at home and abroad about muck improvement in EPB shield tunneling in water-rich sandy cobble stratum, this paper carries out analysis and experiment based on the characteristics of Chengdu water-rich sandy cobble stratum and makes successful application in the project which achieves positive effect of muck improvement. It provides an effective method and the reference for muck improvement in similar shield tunneling, having important guiding significance.

\section{ACKNOWLEDGEMENT}

The research is supported by the National Natural Science Foundation of China (Grant No. 41572245).

\section{REFERENCES}

1. ZHU Wei, CHEN Renjun. Technical Problems and Construction Management of Shield Tunneling [J]. Geotechnical Engineering World, 2001(12): 18-20.

2. LIN Jian, ZHU Wei, ZHONG Xiaochun. 358. Study on the Effect of Foam Stability on Muck Improvement in Shield Tunneling [J]. Geotechnical Engineering World, 2005, 8(12): 38-41.

3. QIN Jianshe, ZHE Wei, LIN Jinye. Assessment of the Foam Application in EPB Shield Tunneling [J]. Underground Space, 2004, 24(3): 350-358.

4. ZHAO Guangzi, JIA Lu, WEN Faqing, CHEN Runshui, XU Xiuting. Study on Muck Improvement Technology for
EPB Shield in Water-rich and Pebbly Sand Stratum in Nan Chang [J]. 1002-8498 (2015) S0-0160-05.

5. MA Liancong. Study on Ground Conditioning for EPB Shield in Water-rich Sandy cobble Ground [J]. 1672-741 X (2010) 04- 0411 -OS.

6. Watson, PJ. Development of a Unique Synthetic Data Set to Improve Sea-Level Research and Understanding [J]. Journal of Coastal Research. 2015, 3(3): 758-770.

7. Elbisy, MS. Sea Wave Parameters Prediction by Support Vector Machine Using a Genetic Algorithm [J]. Journal of Coastal Research. 2015, 31(4): 892-899.

\section{CONTACT WITH THE AUTHOR}

\section{Kai CUI}

Key Laboratory of Transportation Tunnel Engineering of the Ministry of Education Southwest Jiaotong University Chengdu, 610031

CHINA 